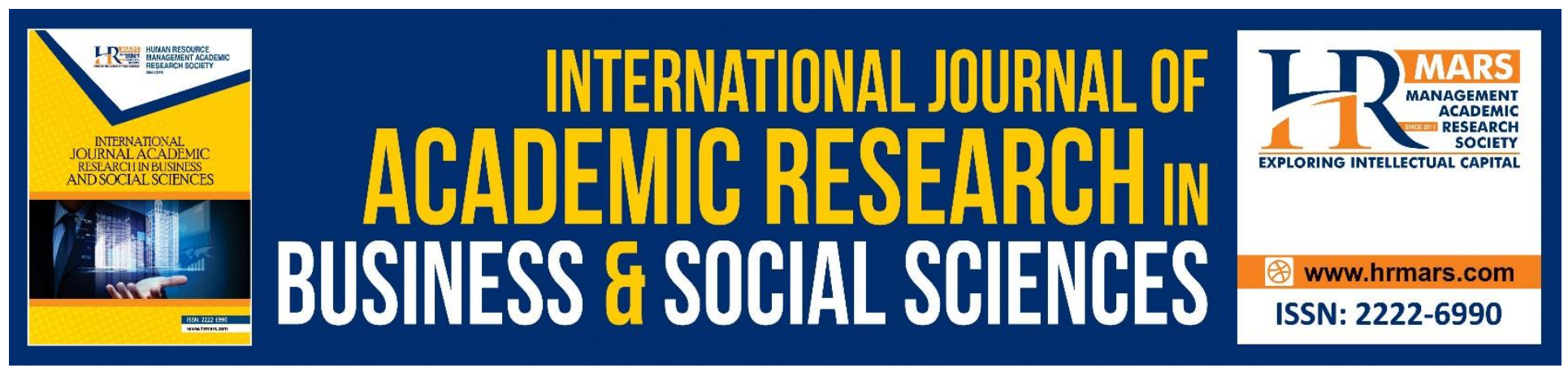

\title{
Pedagogically Aligned Program and its Relationship to the Approaches to Learning: Preservice Teachers' Perspectives
}

\section{Pauline S.C Goh, Yusuf Qismullah, Kung Teck Wong}

To Link this Article: http://dx.doi.org/10.6007/IJARBSS/v8-i10/4778

DOI: $10.6007 /$ IJARBSS/v8-i10/4778

Received: 17 Sept 2018, Revised: 13 Oct 2018, Accepted: 21 Oct 2018

Published Online: 23 October 2018

In-Text Citation: (Goh, Qismullah, \& Wong, 2018)

To Cite this Article: Goh, P. S. ., Qismullah, Y., \& Wong, K. T. (2018). Pedagogically Aligned Program and its Relationship to the Approaches to Learning: Preservice Teachers' Perspectives. International Journal of Academic Research in Business and Social Sciences, 8(10), 774-787.

Copyright: (C) 2018 The Author(s)

Published by Human Resource Management Academic Research Society (www.hrmars.com)

This article is published under the Creative Commons Attribution (CC BY 4.0) license. Anyone may reproduce, distribute, translate and create derivative works of this article (for both commercial and non-commercial purposes), subject to full attribution to the original publication and authors. The full terms of this license may be seen

at: http://creativecommons.org/licences/by/4.0/legalcode

Vol. 8, No. 10, 2018, Pg. $774-787$

Full Terms \& Conditions of access and use can be found at http://hrmars.com/index.php/pages/detail/publication-ethics 


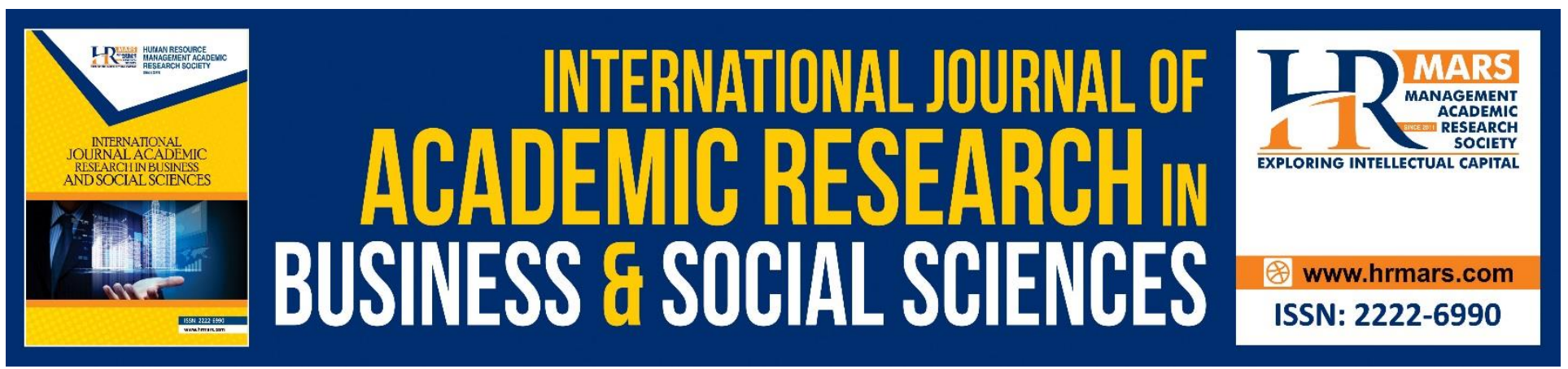

\title{
Pedagogically Aligned Program and its Relationship to the Approaches to Learning: Preservice Teachers' Perspectives
}

\author{
Pauline S.C Goh \\ Sultan Idris Education University, Malaysia,goh.sc@fpm.upsi.edu.my \\ Yusuf Qismullah \\ Syiah Kuala University, Banda Acheh, Indonesia \\ Kung Teck Wong \\ Sultan Idris Education University, Malaysia
}

\begin{abstract}
This study looks at a relatively undeveloped area in teacher education, that of pedagogical alignment. The purpose of this study is therefore to gain more insight into, not only pedagogical alignment in the program, but its relationship between preservice teachers' perceived pedagogical alignment and their approaches to learning. Data were obtained from 446 preservice teachers from two questionnaires, the Malay Language program coherence questionnaire and the re-structured Malay language revised two factor study process questionnaire (R-SPQ-2F). Findings show that the preservice teachers perceived that there is pedagogical alignment in their teacher education program. The preservice teachers also reported higher levels of deep approaches to learning. Correlational analyses showed a relationship between perceived pedagogical alignment and approaches to learning. Through an aligned program, preservice teachers are reporting that they are more likely to be more involved in a deeper understanding of the learning tasks. In addition, they would appear more motivated by an interest in learning or recognition of their vocational relevance. It is heartening to see that an aligned program has an association with preservice teachers deep level approaches to learning. However, teacher educators must remain vigilant to the challenges of how best to harness deep level learning through a sustainable coherence in their teacher education program.
\end{abstract}

Keywords: Teacher Education, Pedagogical Alignment, Approaches To Learning, Preservice Teachers, Preservice Teachers. 


\section{INTRODUCTION}

To allow preservice teachers to integrate the theory and practice of learning, they should be able to explore and comprehend the interdependence of the various elements (e.g. learn how to teach and what it means, understand impacts of teaching on students, assess and reflect one's own teaching) within the teacher education program resulting in the construction of their own professional understanding (Korthagen, Loughran \& Russell, 2006). Therefore, an aligned pedagogical teacher education program will assist preservice teachers' understanding and integration of the new and complex demands and ideas they may encounter across the settings in which they learn. In 2010, a teacher education university in Malaysia restructured its curriculum to better align the theoretical studies and practical experiences of their preservice teachers. What has been found is that when preservice teachers are given the opportunities to bridge theoretical concepts learnt in the campus and to be able to enact and then link those theories during their practicum in schools, they had a positive sense of teaching efficacy (Goh \& Canrinus, forthcoming). Preservice teachers' feelings of positive efficacy in turn contributed to a positive stance towards their own functioning as teachers. However, what is not known is how these preservice teachers approach their learning in this new environment with its restructured curriculum. The present study reports the relationship between preservice teachers' perception of a pedagogically aligned teacher education program and their approaches to learning.

\section{THEORETICAL CONCEPTS}

\section{Program alignment}

Although program alignment is often advocated as the solution to fragmentation or the theorypractice gap in teacher education, the term coherence itself is rarely systematically explored or methodologically defined in the literature. For instance, only a few scholars have offered elaborated definitions of alignment. Tatto (1996) offered a useful definition of program alignment as the degree to which central ideas regarding teaching and learning are shared by all the individuals involved in educating teachers and the degree to which learning opportunities are organized both conceptually and logistically toward those goals. This definition represent coherence according to concepts - ideas or visions, but also according to structures - logistics or design of learning opportunities. Although it is important not to reduce alignment to mere "consistency" (Buchmann \& Floden, 1993), these definitions emphasize it as the connection of ideas and learning opportunities.

Darling-Hammond (2006) provided a vision of what a pedagogically aligned teacher preparation program might look like. Her description highlighted both conceptual and structural alignment as well as the mechanisms that might be important for faculty and students to develop shared visions of teaching and learning. From her perspective, an aligned program offers coursework that is:

... carefully sequenced based upon a strong theory of learning to teach; courses are designed to intersect with each another, are aggregated into a well-understood land-scape of learning, and are tightly interwoven with the advisement process and students' work in schools. Subject matter learning is brought together with content pedagogy through courses that treat them together; pro- gram sequences also create cross-course links. 
Faculty plan together and syllabi are shared across university divisions as well as within departments. Virtually all of the closely interrelated courses involve applications in classrooms where observations or student teaching occur. These classrooms, in turn, are selected because they model the kind of practice that is discussed in courses and advisement. In such intensely coherent programs, core ideas are reiterated across courses and theoretical frameworks animating courses and assignments are consistent across the program. (p. 306)

\section{Deep approach to learning is important to pre-service teachers}

Learners who are deep approach learners show a deeper level of the acquisition of generic skills such as critical thinking, ability to problem solve and an aptitude for reflective thinking (Goh, 2008; Gordon, Simpson, \& Debus, 2001). Gordon and Debus (2002) have indicated that how pre-service teachers approach their learning is also able to influence how they will perform as in-service teachers. Beginning teachers whose learning processes are formed through the use of deep approaches to learning tend to demonstrate greater resilience when confronted with the complexities of teaching and exhibited more confidence in their early years in the profession (Gordon \& Debus, 2002). Goh (2016) has shown that pre-service teachers who have a strong sense of teaching self-efficacy perceive that all students are teachable leading to the application of adaptive problem-solving strategies and high academic achievement. Attainment of strong self-efficacy requires a deep approach. In addition, deep learning approaches also imply higher cognitive processes and are consistent with constructivist views of learning wherein pre-service teachers set out to solve problems in novel circumstances (Petegem, Donche \& Vanhoof, 2005). On the other hand, pre-service teachers who are immersed in a learning environment which encourages deep approaches to learning are more likely to practice a constructivist method of teaching, thus Petegem, Donche and Vanhoof (2005) suggest that it would be beneficial to encourage deep processing strategies among pre-service teachers. However, in most teacher education in Malaysia, considerable attention is generally given to the learning the pedagogy of teaching, and generally to ensure that potential teachers demonstrate competence in their areas of specialisation. Little attention is given to the impact such activities have on the way pre-service teachers learn. Considering the importance of deep approach to learning on learning outcomes, it would seem necessary for practice to better understand these associations which can then be expanded to innovations or changes to teacher preparation.

Yet despite this increasing emphasis on developing coherent teacher preparation programs, and the importance of approaches to learning, the ingredients of coherence and approaches to learning remain a relatively underexplored area by researchers in teacher education. Although a few researchers have examined the practices and learning of graduates in teacher programs (e.g. McDonald, 2005; Tatto, 1996), such research is rare, and the specific factors that contribute to coherence and its relationships to approaches to learning remain unclear. In particular, although discussions of reform in teacher preparation often centre on coherence as a means to bridge the gap between field-work and clinical work, research on coherence has not yet examined if a coherent program equates to deep learning approaches. Therefore, this study sets out to answer the following questions: 
INTERNATIONAL JOURNAL OF ACADEMIC RESEARCH IN BUSINESS AND SOCIAL SCIENCES

Vol. 8, No. 10, Oct. 2018, E-ISSN: 2222-6990 @ 2018 HRMARS

1. How much approaches to learning do the preservice teachers report?

2. How aligned do the preservice teachers experience their teacher education program to be?

3. To what extent are the preservice teachers' perceptions of a pedagogically aligned program and their approaches to learning related?

\section{METHODOLOGY}

\section{The preservice teachers}

The 446 preservice teachers in this study, with mean age of 24 (SD =0.88, Min: 22 years; Max: 29 years), came from a teacher education university located in the state of Perak, Malaysia. Ethical approval to conduct the study was obtained from two review boards which were given detailed information on data collection procedure. The teacher preparation program in this university consisted of a sequence of university courses from the first to the sixth semesters, followed by a 16 week practicum experience in selected government schools in their seventh semester. The participants in the present study were prepared to become secondary school teachers and had declared an academic major and minor. They had recently returned to the university for their eighth and final semester upon completion of their practicum when this study was carried out.

To ensure that the sample was appropriate for the analyses, the Kaiser-Meyer-Olkin (KMO) measure of sampling adequacy index was conducted and presented an index of 0.87 . A significant result of $x^{2}=1392.8, p<0.01$ was found for the Bartlett's test of Sphericity.

\section{Data Collection}

Data were collected from 446 candidates from two questionnaires. They were the 30 -item Malay language program coherence questionnaire and the restructured 17-item Malay language Revised Two-Factor Study Process Questionnaire.

\section{The Malay Language program coherence questionnaire}

The Bahasa Melayu (Malay Language) program coherence questionnaire (BM-CATE) was a modified version of the original 38-item Coherence and Assignment Study in Teacher education (CATE) questionnaire designed by Kirsti Klette, Inga Staal Jenset, Karen Hammerness and Ogla Kristian Bergen in 2014 at the University of Oslo. The questionnaire set out to evaluate the overall integration of the theoretical components of the teacher preparation programs with that of key components that can assist preservice teachers' practice. CATE attempts to measure the 'theory-into-practice' view of teacher education such as discrepancies between theory and practice, experiences preservice teachers received during their practicum and the practicalities of learning how to teach.

Our translated BM_CATE consisted of 30 items (of a four factor model) which looked at whether preservice teachers had opportunities to practice activities that were very close to the real work of teaching such as to study subject curriculum, analyze pupils' school work, view videos of classroom teaching, investigate materials related to classroom practices and to analyse their own learning. In 
addition, the questionnaire was designed to also look at whether the program enabled the preservice teachers to make explicit connections between campus courses and their practicum. The first dimension had 7 items and was named 'Opportunity to enact practice' (Cronbach alpha $=0.79$ ). It evaluated whether the preservice teachers had opportunity to: 'Connect ideas from one class to another in the same program', and 'Connect ideas from one course to those in another'. The second dimension was called 'Opportunity to analyse practice' ( 6 items, Cronbach alpha $=0.86$ ). Examples of the items for this factor were: 'The program articulated clear vision of teaching and learning' and 'I heard similar views about teaching and learning across the program courses'. The third factor was termed 'Opportunity to connect ideas across courses' (5 items, Cronbach alpha $=0.83$ ). It looked at whether preservice teachers perceived that their education courses provided opportunities for them to connect one idea to another from different courses, know the vision of good teaching advocated by the teacher education and to be able to project their own trajectory of learning. The fourth and final factor was called 'Coherence between courses and practical experience' (12 items, Cronbach alpha $=0.85$ ) and measured if the same theories, strategies and techniques preservice teachers learnt during their coursework were used during their practicum. Confirmatory Factor Analysis (CFA) using SPSS Amos 20 was conducted to verify if the four factor model could be validated. The results showed that the data set fits the four factor model reasonably well with values of 0.90 and greater for the $\mathrm{GFI}, \mathrm{CFI}$ and TLI and values of RMSEA at 0.05 (chi square / $\mathrm{df}=2.22$ ).

\section{Malay language Revised Two-Factor Study Process Questionnaire}

The Bahasa Melayu (Malay language) Revised Two-Factor Study Process Questionnaire (or BM-RSPQ-2F) was a translation of the Biggs. Kember and Leung's Revised two Factor Study Process Questionnaire (R-SPQ-2F) (2001). The R-SPQ-2F was modified and refined from the original Study Process Questionnaire (SPQ) (Biggs, 1987). The theoretical framework of the SPQ consisted of three approaches to learning, namely, deep, surface and achieving dimensions, each with its own motive and strategy subscales. However when the SPQ was used with Hong Kong students, it was found that the SPQ resulted in two dimensions, which were deep and surface approaches rather than with three dimensions. Based on this new information, Biggs, Kember and Leung (2001) further refined the SPQ and named it R-SPQ-2F with 20 items and were scored on a 5 point Likert scale and categorized students into deep approaches to learning or surface approaches to learning, each containing two subscales, 'motive' and 'strategy'. Their results also found reasonably good reliability coefficients and goodness of fit for either a two factor model or a four factor model.

The BM-R-SPQ-2F translation resulted in acceptable Cronbach's alpha values for 17 items, instead of 20 items, for a four factor model. The subscales motive and strategy were renamed to better reflect the new 17 items BM-RSPQ-2F and its use for Malaysian preservice teachers. The deep motive and deep strategy (deep approaches to learning) were named 'Learning with Interest' (6 items, Cronbach's alpha $=0.74)$ and Learning with Satisfaction $(3$ items, Cronbach's alpha $=0.64$ ) respectively, while the surface motive and surface strategy (surface approaches to learning) were termed 'Learning with Minimal Effort' (5 items, Cronbach alpha $=0.66$ ) and 'Learning through Memorizing' (Cronbach alpha $=0.56$ ) respectively. All the newly labeled subscales had alpha ranged 
from 0.54 to 0.75 with a medial of 0.65 and therefore, had acceptable reliability for research purposes (Nunnally \& Berstein, 1994). All four newly termed subscales were used in the analyses. Confirmatory Factor Analysis (CFA) using SPSS Amos 20 was conducted to verify if the four factor model could be validated. The results showed that the data set fits the four factor model reasonably well (chi-square $/ \mathrm{df}=1.52, \mathrm{GFI}=0.93, \mathrm{AGFI}=0.91, \mathrm{CFI}=0.93, \mathrm{SRMR}=0.05, \mathrm{RMSEA}=0.05)$.

Items in 'Learning with Interest' evaluated if pre-service teachers were motivated to work hard because they have interest in their learning, used strategies such as "looking at most of the suggested readings", "spend extra time trying to obtain more information" or "finding out more about interesting topics which have been discussed in different classes". Inversely, "Learning with Minimal Effort" measured the preservice teachers perceived interest in learning because they did not want to get into trouble for not doing their work and therefore, spend very little time in their studies as in the statement "restrict my study to what is specifically set". "Learning with Satisfaction" evaluate preservice teachers perceived satisfaction in learning (for example through statements such as: "I find that at times studying gives me a feeling of deep personal satisfaction" or "I test myself on important topic until I understand them completely"). In contrast, the factor "Learning through Memorizing" measured those preservice teachers who wanted to "get-by" or "pass examinations" and would use memorization. All items are positively worded so that no recoding is necessary when scoring the questionnaire. Subscale scores range from five to 25 with higher scores indicating those who make a greater use of that approach to learning.

\section{Analyses}

Two types of analyses were conducted. Descriptive statistics was used to answer the first and second research questions, while a correlation matrix was conducted to discover any significant relationships between program coherence and approaches to teaching.

\section{RESULTS}

Results were analyzed by means of descriptive statistics for the measures used in the present study and by correlation analysis to gauge the relationships between preservice teachers' approaches to learning and their perceived coherence in their teacher education program. Table 1 presents descriptive statistics for the measures used in the present study. 
INTERNATIONAL JOURNAL OF ACADEMIC RESEARCH IN BUSINESS AND SOCIAL SCIENCES

Vol. 8, No. 10, Oct. 2018, E-ISSN: 2222-6990 ㄷ 2018 HRMARS

Table 1

Descriptive statistics for the main measures used

\begin{tabular}{|c|c|c|}
\hline Measures & Mean & SD \\
\hline \multicolumn{3}{|l|}{ Perception of an aligned program } \\
\hline Opportunity to enact practice & 3.11 & 0.48 \\
\hline Opportunity to analyze practice & 3.00 & 0.55 \\
\hline Opportunity to connect ideas across courses & 3.15 & 0.54 \\
\hline $\begin{array}{l}\text { Coherence between courses and practical } \\
\text { experience }\end{array}$ & 3.24 & 0.39 \\
\hline \multicolumn{3}{|l|}{ Approaches to learning } \\
\hline Learning with Interest & 3.62 & 4.37 \\
\hline Learning with Minimal Effort & 3.03 & 4.24 \\
\hline Learning with Satisfaction & 3.62 & 2.22 \\
\hline Learning through Memorization & 3.29 & 2.64 \\
\hline
\end{tabular}

Preservice teachers' had similar scores for "Learning with Interest" $(M=3.62)$ and "Learning with Satisfaction" ( $M=3.62)$ and were both higher than their scores for "Learning with Minimal Effort" $(M=3.03)$ and "Learning through Memorization" $(M=3.29)$, whereby "Learning with Minimal Effort" had the lowest score. For the perceived program coherence, "Coherence between courses and practical experience" $(M=3.24)$ had the highest score, followed by "Opportunity to connect ideas across courses" $(M=3.15)$. The third highest score was "Opportunity to enact practice" $(M=3.11)$. The perception of whether preservice teachers had opportunity to use theories learnt, use it in some form to analyze practice had the lowest score $(M=3.00)$.

Correlational analysis revealed significant relationships between candidates' perception of perceived coherence and components of their approaches to learning (see Table 2). Zooming in on the candidates' perceived "Opportunity to enact practice", this scale showed a significant positive correlation with the deep approaches to learning, but a mixed relation with the surface approached to learning (i.e. "learning through memorization": $r=0.37$; "learning with minimal effort": $r=-0.23$ ). Preservice teachers' "Opportunity to analyze practice" gave similar results. Regarding deep learning approaches, "Opportunity to analyze practice" was only positively related to learning with satisfaction ( $r=0.23)$. Regarding surface learning, the relation with learning with minimal effort $(r=-$ 
0.33) was negative yet positive with learning through memorization ( $r=0.28)$. "Opportunity to connect ideas across courses" had positive correlations with the two components of deep approaches to learning but a significant negative correlation with "Learning with minimal effort" ( $r=-0.33)$. Similar significant positive correlation was found between "Coherence between courses and practical experience" and the deep approaches to learning, however, it also indicated a significant positive correlation with the surface approach to learning through "Learning through Memorization" $(r=0.21)$.

Table 2

Correlations among the measures used in the study

\begin{tabular}{lllllllll}
\hline Measures & 1 & 2 & 3 & 4 & 5 & 6 & 7 & 8
\end{tabular}

Perception of an

aligned program

1. Opportunity 1

to Enact Practice

2. Opportunity $.57^{*} 1$

to analyse practice *

3. Opportunity $.65^{*} \quad .63 * * \quad 1$

to connect ideas *

across courses

and practical

experience

Approaches to

learning

$\begin{array}{lllllll}5 . \quad \text { Learning with } & .39 * & .17 & .29 * & .29 * & 1 \\ \text { Interest } & * & & & * & \end{array}$

6. Learning with $-.23 *-.33 * *-28.19 \quad .28 * 1$

Minimal Effort $.22 * \quad *$

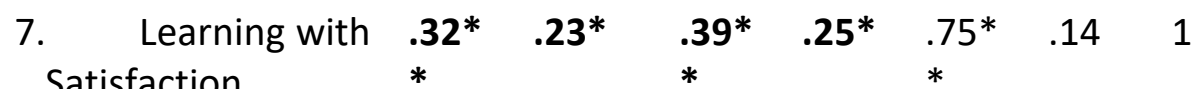

$\begin{array}{lllllllll}8 . \quad \text { Learning } & .37 * & .28 * * & .19 & .21 * & .49 * & .54 * & .40 * & 1 \\ \text { through } & * & & & & * & * & * & \end{array}$

Memorization

$* p<0.05 * * p<0.01$ 


\section{DISCUSSION}

In the present study we investigated: a) the approaches to learning of preservice teachers; $b$ ) the pedagogical alignment as perceived by the preservice teachers, and c) the relationships between preservice teachers' approaches to learning and their perceived pedagogical alignment. The preservice teachers in this study showed higher scores for learning with interest and that they derived satisfaction from learning - and these are all indications of deep approaches to learning. With deep approaches to learning, preservice teachers are able to extend and deepen prior knowledge and existing knowledge from their learning and adjust and refine understandings. According to Biggs, Kember and Leung (2001), with deep level learning, learners are more able to apply learning in different contexts and thus allowing then to examine what they know and generalize learning. It can be said that for preservice teachers, such ability is doubly important as their prior knowledge of teaching generally are limited by their own experiences as students in schools. Therefore, preservice teachers' preponderance towards deep learning will benefit them greatly in their ability to engage with in-depth understandings of new knowledge and to apply what is learned in campus into their new contexts- in this case the classrooms. For those who indicate that they are surface learners, there is the danger that such preservice teachers are not motivated towards new conceptual understandings and critical inquiry towards teaching but instead possess extrinsic motivation and values towards passing or avoidance of failure only. There is a risk that these preservice teachers will become irrelevant and underperform as teachers of the 21st century.

With regards to program alignment, the preservice teachers reported that generally, there were alignment in their teacher education program. There were alignment between what they have learnt on campus and being able to use it during their practicum which had the highest score. These bode well for the current program at the university under which this study was carried out. According to Darling-Hammond (2014), it is important that there must be alignment between learning how to teach and when they are in the actual teaching scenario. Way back in 1904, Dewey has argued that practicum should not the start of how teachers learn how to teach, but instead, it is the time preservice teachers put into practice the theoretical perspectives they have acquired.

Having opportunities to connect knowledge learnt in one course within the program to other courses had the next highest score. How well the different educational courses are integrated is equally important to the quality of the program (Darling-Hammond, 2014; Falkenberg, Goodnough \& MacDonald, 2015). Benefits of program coherence have been evidenced in various outcomes including teaching efficacy (Geoghegan, Geoghegan, O'Neill \& White, 2004; Goh \& Canrinus, forthcoming) and teacher effectiveness (Othman \& Md Salleh, 2016). More often than not, courses within a teacher education is a compartmentalized course offering and educators expertise is usually confined to a single content area (Cabaroglu, 2014).) Similarly, novice teachers have indicated they would they have liked more alignment between theory and practice during their teacher preparation program, as more times than not, there is a perception of teaching being compartmentalized and fragmented (Goh, Yusuf \& Wong, 2017). 
Opportunity to Enact Practice and Opportunity to analyse practice held the last two highest scores respectively. For this group of preservice teachers, they do perceive that they had opportunities to enact practice and also opportunities to analyse their students' work. The importance of perceiving these two opportunities relates to being given the chance to practice teaching skills and to assist them in making connections between their campus learning and their subsequent practicum. Being given the opportunities to enact practice enables the preservice teachers to try out various teaching skills such as leading students, giving feedback, conducting questions and answers session to enhance critical thinking among students. It is important that preservice teacher feel safe while 'rehearsing' teaching skills and that they are able to experience the learning process or "the way" towards being a teacher.

The results of the correlational analysis indicated positive relationships between preservice teachers' perception of alignment and the components of deep approaches to learning and a negative relationship with Learning with Minimal Effort (a surface approach dimension). Possibly, an aligned program enabled the preservice to have a better comprehension of what had been learned. This could also indicate that when they felt that when they had opportunities to better understand how teaching practices were carried out and how theories were aligned to practice, it enabled them to also examine and to relate different ideas about teaching. Through an aligned program, preservice teachers are reporting that they are more likely to be more involved in the learning tasks. They would appear more motivated by an interest in learning or recognition of its vocational relevance. It must be noted that teacher education differs from other tertiary level programs. The procedural nature of learning in other tertiary subjects is no longer the focus in teacher education, instead preservice teachers are required to delve deeper, and understand the reasoning behind the many teaching theories and perspectives, and then being able to make judgment of its use in actual teaching situation. This change can appear to be quite shocking to certain preservice teachers. However, a combination of consistent and cohesive direction throughout the program can mitigate the early traumas of preservice teachers (Goh \& Blake, 2015; McMillan, 2012).

The use of Learning through Memorization (another dimension of surface approach to learning) is found to be positively correlated with perceived alignment. This may appear contrary to expectations as it may be expected that a coherent program may reduce students' reliance on rote learning. However, Kember and Ginns (2012) caution that students need not reduce their use of rote learning when adopting a deep approach as in some learning contexts, such surface learning is required in order to progress to higher levels of understanding. McCune and Entwistle (2000) write that "in the science areas, the deep approach appeared to require an initial concentration on details which seemed in some ways similar to the surface approach" (p. 13). This is in line with the "Chinese learner paradox' identified by Kember and Gow (1990), whereby a certain amount of memorisation formed part of a deep approaches to learning.

\section{CONCLUSION}

This study used an adapted Bahasa Melayu (Malay Language) program coherence questionnaire (BMCATE) and the Bahasa Melayu R-SPQ-2F to obtain preservice teachers' perceptions of their teacher 
education program and then to identify if there was a relationship between a perceived pedagogically aligned program with their approaches to learning. The findings showed that, at least for this group of preservice teachers, they have perceived alignment within their program. The findings also reflected the contextualized nature of approaches to learning. Preservice teachers tended to adopt a deeper level of learning when they perceived that their program and courses to be aligned with a connection between theory and practice.

The multifaceted nature of building program alignment is not an easy task. Bringing curriculum, theory and practices into alignment takes time and demands initiatives that is not easily won. However, this study illustrates the complex manner in which preservice teachers are more predisposed towards deep level learning by their educational experiences, in this case, that they felt that they had opportunities to learn about actual classroom practices, chances to analyze their students' work and could experience the connection between theory and practice. Effective teacher education program is clearly needed to support and sustain preservice teachers' work in enabling them to be ready to face the many challenges of teaching in the 21st century, but, making teacher education program more aligned seems very compelling in this new era.

\section{ACKNOWLEDGEMENTS}

The first author is grateful to AFI EDUCATION FOUNDATION for providing the grant that has enabled the authors to carry-out this study and to further improve teacher education.

\section{REFERENCES}

Biggs, J.B. (1987). Student Approaches to Learning and Studying. Melbourne: Australian Council for Educational Research

Biggs, J.B., Kember, D., \& Leung, D.Y.P. (2001). The revised two-factor Study Process Questionnaire: R-SPQ-2F. British Journal of Educational Psychology, 71(1), 133-149. doi: 10.1348/000709901158433

Buchmann, M., \& Floden, R. E. (1991). Programme coherence in teacher education: A view from the USA. Oxford Review of Education, 17(1), 65-72. doi:10.1080/0305498910170105

Cabaroglu, N. (2014). Re-visiting the theory and practice gap through the lens of student teacher dilemmas. Australian Journal of Teacher Education (Online), 39(2), 89-109. doi: 10.14221/ajte.2014v39n2.10

Darling-Hammond, L. (2006). Powerful teacher education: Lessons from exemplary programs. John Wiley \& Sons. San Francisco, CA: Jossey-Bass.

Darling-Hammond, L. (2014). Strengthening clinical preparation: The holy grail of teacher education. Peabody Journal of Education, 89(4), 547-561. doi: 10.1080/0161956X.2014.939009 
INTERNATIONAL JOURNAL OF ACADEMIC RESEARCH IN BUSINESS AND SOCIAL SCIENCES Vol. 8, No. 10, Oct. 2018, E-ISSN: 2222-6990 ㄷ 2018 HRMARS

Falkenberg, T., Goodnough, K., \& MacDonald, R. J. (2015). Views on and practices of integrating theory and practice in teacher education programs in Atlantic Canada. Alberta Journal of Educational Research, 60(2), 339-360.

Geoghegan, N., Geoghegan, D., O'Neill, S., \& White, R. (2004). Preservice early childhood teachers' self-efficacy, teacher preparedness and facilitating children's learning of concepts in multiple contexts. Paper presented at the Australian Association for Research in Education, Melbourne, November 28.

Goh, S.C. (2008). Teaching Practices that Hinder the Deep Approaches to Learning of Twinning Programme Students in Malaysia: A Qualitative Perspective. The Asia-Pacific Education Researcher 17(1 ), 63-73. doi: 10.3860/taper.v17i1.350

Goh, P.S.C. (2016). Preservice teachers' approaches to learning and their learning outcomes: A Malaysia experience. In R.B. King \& A.B.I. Bernardo (Eds), The Psychology of Asian Learners: $A$ Festschrift in honor of David Watkins (pp. 203-216). Springer: Singapore.

Goh, P. S. C., \& Blake, D. (2015). Teacher preparation in Malaysia: Needed changes. Teaching in Higher Education, 20(5), 469-480. doi: 10.1080/13562517.2015.1020780

Goh, P.S.C., Yusuf, Q., \& Wong, K.T. (2017). Lived Experience: Perceptions of Competency of Novice Teachers. International Journal of Instruction, 10(1), 20-36. doi: 10.12973/iji.2017.1012a

Goh, P.S.C., \& E.T. Canrinus. (forthcoming). “Preservice Teachers' Perception of Program Coherence and its Relationship to their Teaching Efficacy." Pertanika Journal of Social Science \& Humanities.

Gordon, C., \& Debus, R. (2002). Developing deep learning approaches and personal teaching efficacy within a preservice teacher education context. British Journal of Educational Psychology, 72(1), 483511. doi: 10.1348/00070990260377488

Gordon, C., Simpson, T., \& Debus, R. (2001). Improving quality learning in a pre-service teacher education program. Retrieved from http://www.aare.edu.au/01pap/gor01441.htm

Kember, D., Ginns, P. (2012). Evaluating Teaching and Learning. London: Routledge.

Kembr, D., \& Gow, L. (1990). Cultural specificity of approaches to study. British Journal of Educational Psychology, 60(3), 356-363. doi: 10.1111/j.2044-8279.1990.tb00952.x

Othman, I., \& Md Salleh, N. (2016). Relationship between student teachers' achievement in professional education courses and their achievement in teaching practices. Journal of Research, Policy \& Practice of Teachers \& Teacher Education, 6(2), 5-15. 
INTERNATIONAL JOURNAL OF ACADEMIC RESEARCH IN BUSINESS AND SOCIAL SCIENCES

Vol. 8, No. 10, Oct. 2018, E-ISSN: 2222-6990 ㄷ 2018 HRMARS

Korthagen, F., Loughran, J., \& Russell, T. (2006). Developing fundamental principles for teacher education programs and practices. Teaching and Teacher Education, 22(8), 1020-1041. doi: 10.1016/j.tate.2006.04.022

McCune V. \& Entwistle, N.J. (2000). The deep approach to learning: analytic abstraction and idiosyncratic development. Paper presented at the 'Innovations in Higher Education' conference, 30 August - 2 September 2000, Helsinki.

McDonald, M. (2005). The integration of social justice in teacher education: Dimensions of prospective teachers' opportunities to learn. Journal of Teacher Education, 56(5), 418 - 435. doi: $10.1177 / 0022487105279569$

McMillan, J. (2012). Examining creativity in teacher training: Perspectives from music Education. Journal of Research, Policy \& Practice of Teachers \& Teacher Education, 2(1), 16-32.

Nunnally, J.C., \& Berstein, I.H. (1994). Psychometric Theory (3rd ed.). Sydney: McGraw Hill.

Petegem, P.V., Donche, V., \& Vanhoof, J. (2005). Relating pre-service teachers' approaches to learning and preferences for constructivist learning environments. Learning Environments Research, 8(3), 309332.

Tatto, M.T. (1996). Examining values and beliefs about teaching diverse students: Understanding the challenges for teacher education. Educational Evaluation and Policy Analysis, 18(2),155-180. doi: 10.3102/01623737018002155 